\title{
AN SHCC OVERLAY RETROFITTING STRATEGY FOR UNREINFORCED LOAD BEARING MASONRY
}

\author{
GIDEON P.A.G. VAN ZIJL ${ }^{*}$ AND LEON DE BEER ${ }^{\dagger}$ \\ * Stellenbosch University (SUN), South Africa \\ e-mail: gvanzij1@sun.ac.za \\ ${ }^{\dagger}$ Stellenbosch University (SUN), South Africa \\ e-mail: 1debeer@sun.ac.za
}

Key words: SHCC, Masonry, Overlay, Bond, Fracture Energy

\begin{abstract}
In the Western Cape Province of South Africa, multi-storey buildings of unreinforced load bearing masonry (ULM) were constructed before seismic resistance became a standardized requirement. The region lies in a light to moderate seismic zone in South Africa. It is foreseen that these buildings might perform poorly during seismic events due to their brittle in-plane shear failure mode. In response, a research project was launched to develop an overlay retrofitting strategy to enhance seismic resistance of ULM. As overlay material, strain-hardening cement-based composites (SHCC) is used. In this paper, a preferred failure mechanism is described and designed for by restricting the overlay thickness to allow multiple crack formation in the overlay, instead of overlay debonding. The strategy is verified by a triplet-type test on control masonry specimens, and two sets of specimens with $10 \mathrm{~mm}$ and $30 \mathrm{~mm}$ SHCC overlays respectively.
\end{abstract}

\section{INTRODUCTION}

In the Western Cape Province of South Africa, a light to moderate seismic zone in South Africa ${ }^{[1]}$, multi-storey buildings of unreinforced load bearing masonry (ULM) were built before seismic resistance became a standardized requirement. These buildings are expected to perform poorly in seismic events. Stellenbosch University has launched a research project to develop an overlay retrofitting strategy to enhance seismic resistance of ULM structures. As overlay material, strain-hardening cementbased composites (SHCC) is proposed ${ }^{[2]}$. For practical application of the overlay, material development was done to produce a shotcrete version, optimized for sprayability and adhesion to the masonry.
Empirical testing has been performed recently ${ }^{[3]}$ to study various parameters of such a retrofitting strategy, including the number of ULM wall leafs and overlay thickness. Recent research on SHCC overlay bond ${ }^{[4]}$ showed that the bond characteristics and interaction with multiple crack formation in the SHCC overlay are sensitive to substrate surface preparation. In a strategy to increase seismic resistance, multiple crack formation in the overlay is preferred, as this mobilizes significant ductility and energy dissipation of the proposed structural system. In order to determine an appropriate balance between the ULM-SHCC interface properties and those of the SHCC overlay, SHCC multiple shear cracking and interfacial debonding failure modes are studied and characterised here. The approach is verified on ULM specimens with two SHCC overlay 
thicknesses. The thinner overlay thickness is designed to mobilise multiple cracking in the overlay, while the second, larger thickness is designed to debond from the masonry in a shear-dominated test.

\section{MASONRY SHEAR MECHANICS}

In-plane shear of masonry wall parts has been studied by various authors, eg. Vermeltfoort et al. (1993) ${ }^{[5]}$, Van der Pluijm $\left(1992^{[6]}, 1998^{[7]}\right)$ and Van Zijl et al. $(2001)^{[6]}$ due to its importance in bearing lateral loads caused by seismic or wind excitation. Two dominant cracking patterns for masonry with relatively weak joints are shown in Fig. 1 together with a typical laboratory shear test setup. The setup simulates pressure from upper storeys, and is to be distinguished from a reinforced concrete or steel framed structure with masonry infill.

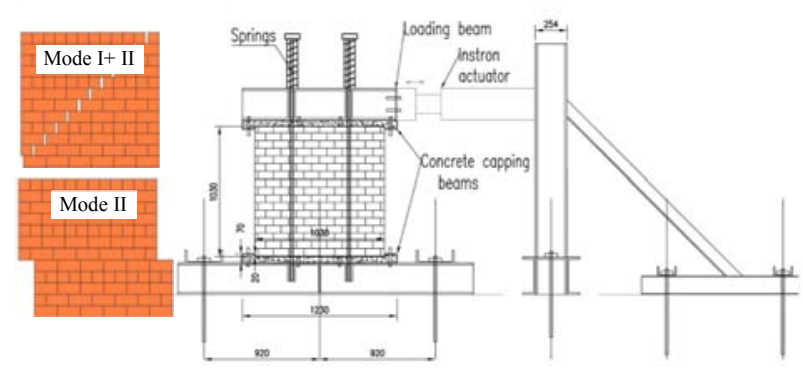

Figure 1: Masonry wall part shear crack patterns and a typical laboratory shear test setup.

From Fig. 1 tensile cracking in the head joints, Mode I, and shear-slipping along bed joints, Mode II, are evident. A computational model to capture these mechanisms has been proposed by van Zijl (2004) $)^{[9]}$, combining a strain-softening Coulomb-friction limit function and a softening tensile cut-off. The shearing mode captures the dilatant uplift of masonry units upon shear-slipping, as a potential function in the multi-surface plasticity formulation. The dilatancy model captures the physical phenomena shown in Fig. 2. The dilatancy coefficient $\Psi$, which captures the inelastic vertical uplift $u_{p}$ upon inelastic horizontal shear-slipping displacement $v_{p}$, gradually reduces with shear-slipping displacement. It also reduces with increased normal pressure, linked to abrasion of the shearing interface by slipping under normal pressure. The dilatancy coefficient can be expressed as:

$$
\Delta u_{p}=\Psi \Delta v_{p}
$$

with

$$
\Psi=\left\{\begin{array}{cc}
0 & \sigma<\sigma_{u} \\
\Psi_{0}\left[1-\frac{\sigma}{\sigma_{u}}\right] e^{-\delta v_{p}} & \sigma_{u} \leq \sigma<0 \\
\Psi_{0} e^{-\delta v_{p}} & \sigma_{u} \geq 0
\end{array}\right.
$$

where $\Psi_{0}$ is the initial dilatancy coefficient at zero shear slip, $\sigma_{u}$ is the normal stress at which the the dilatancy becomes zero and $\delta$ is the dilatancy shear-slip degradation coefficient.

Significant pressure build-up and associated increased frictional resistance in the bed joints may accompany prevention of uplift in framed systems.

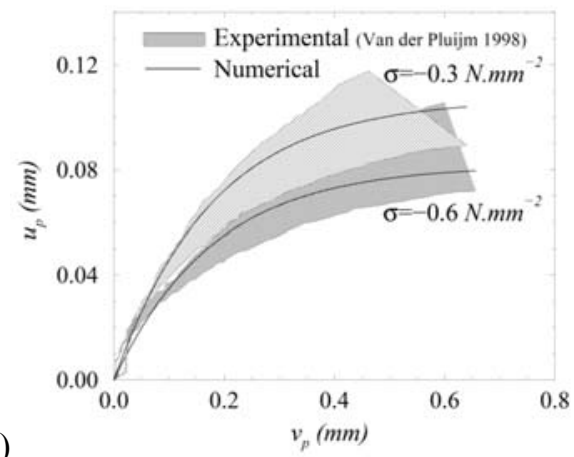

(a)

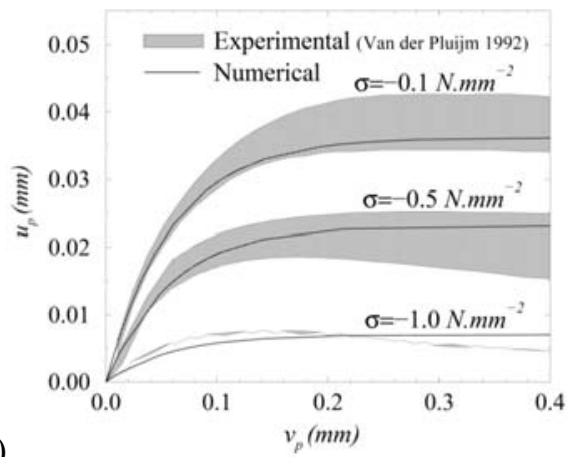

Figure 2: Masonry dilatant uplift upon shearing displacement along a mortar joint for (a) clay brick and (b) calcium silicate masonry. 


\section{SHCC AND OVERLAY MECHANICS}

SHCC bonded overlays have been shown to significantly increase in-plane resistance and ductility of concrete (Stander \& van Zijl 2009) $)^{[4]}$ and masonry (Lin 2014) $)^{[3]}$. The overlay acts as reinforcement, in the case of masonry walls, through effectively bridging the mortar joints. In an overlay strategy of applying a bonded SHCC overlay to a masonry wall to improve its in-plane shearing response, it is beneficial to mobilize SHCC multiple cracking in shear to increase ductility and energy dissipation.

\subsection{SHCC tensile and shear behaviour}

Multiple cracking of SHCC is well-known in uniaxial tension (eg. van Zijl et al. 2015) ${ }^{[10]}$, as well as in shear (van Zij1 2007) ${ }^{[11]}$. Significant ductility is evident beyond first cracking of the SHCC matrix. Fig. 3 shows a schematic of multiple crack formation in shear, capturing the increased shear resistance and orientation of shear cracks due to its ability to maintain or increase stress transfer across the fine cracks by fibre bridging. Van Zijl (2007) ${ }^{[11]}$ reported an ultimate shear stress for SHCC of roughly $50 \%$ larger than the ultimate tensile stress.

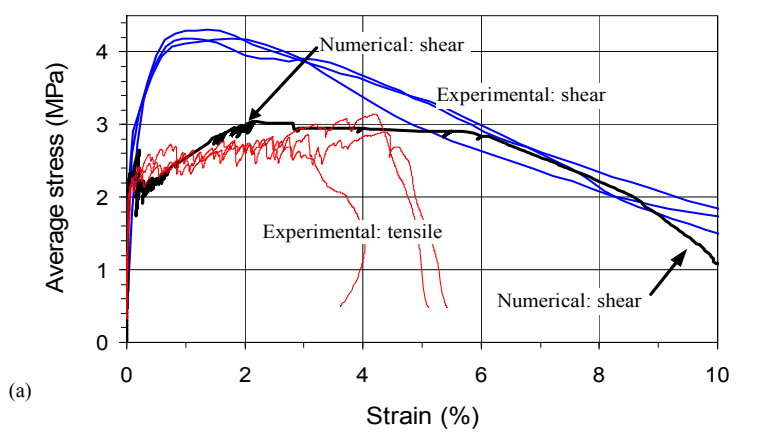

(b)

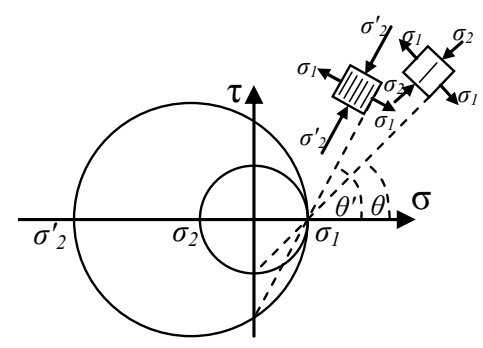

Figure 3: (a) SHCC shear stress-diagonal strain response compared with uniaxial tensile stress-strain response $^{[11]}$. (b) Schematic Mohr circle, showing increased shear stress and crack alignment in SHCC beyond first $\operatorname{crack}^{[11]}$.

\subsection{SHCC overlays on ULM}

The scope of investigation in this contribution is SHCC overlays on ULM. Care is taken to consider the relevant mechanisms to ensure appropriate experimental setups, for instance careful consideration of restraint to dilatant uplift associated with shear-slipping in ULM subject to dominantly lateral loads.

\section{Mode 1: SHCC multiple shear cracking}

With reference to Fig. 3b, multiple cracking in SHCC is a preferred, ductile response to lateral loading. A design guideline should clearly aim at achieving this mechanism as opposed to debonding of an overlay. The latter will treated in more detail in the next section.

Consider the shearing case shown schematically in Fig. 4. Mode 1 failure comprises multiple shear cracking along the shear planes. This is the preferred failure mechanism to mobilise the energy dissipation capacity of SHCC. It requires partial delamination of SHCC from the brick face in the shear zones to allow cracks to form in the SHCC overlays.

\section{Mode 2: Debonding}

Mode 2 is debonding and shear-slipping along the brick interfaces with the mortar and overlay. This is typically a brittle failure mode.

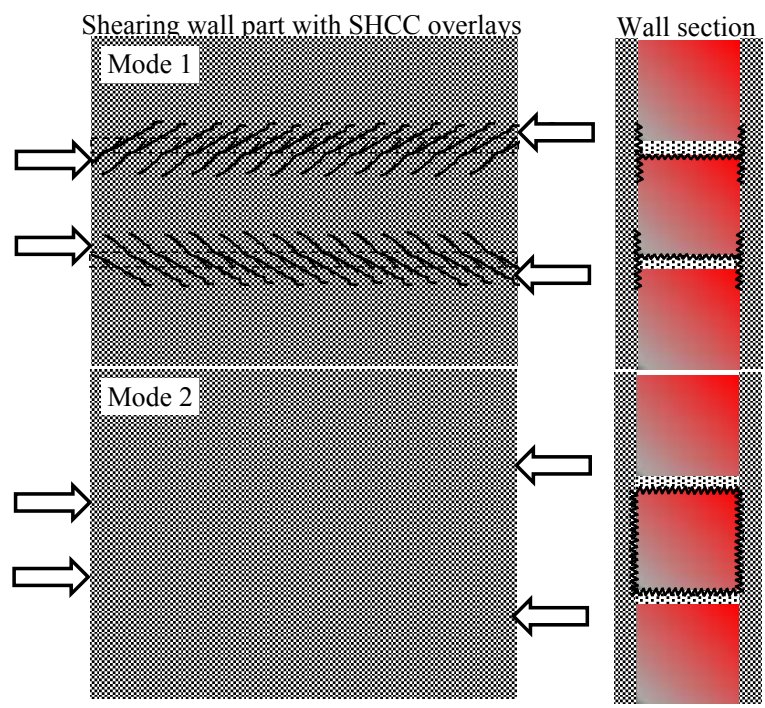

Figure 4: Wall part subject to shear, resembling a triplet test showing failure mode 1 (multiple cracking) and mode 2 (delamination). 
In both failure modes the overlay provides restraint to dilatant uplift of bricks as they shear-slip along the interfaces. For uplift to occur, the overlays must elongate perpendicular to the shearing plane. In mode 1 , crack formation in the SHCC reduces the stiffness significantly, as is evident in Fig. 3a. Thereby, the dilatancy is most likely accommodated without significant pressure and associated shear resistance build up. Also note that the dilatant uplift is typically one order less than the shear-slip - see Fig. 2. In mode 2, more restraint to dilatant uplift is expected, as the overlay may still be in the elastic state. Restrained shrinkage, together with dilatant uplift might cause the tensile strain in the overlay to exceed the elastic limit, at which stage cracks will initiate and the pressure build up partially released.

In the next sections material and model characterisation is performed, after which a test series is designed to exhibit the two failure modes of Fig. 4.

\section{MATERIALS, CHARACTERISATION}

\subsection{SHCC tensile properties}

The mix ingredients and proportions of an SHCC mix suitable for shotcrete application was developed, as summarised in Table 1.

The SHCC and interface properties determined from characterization tests are summarized in Table 2. Dumbbell specimens with central cross-section dimensions of $40 \mathrm{~mm}$ x $80 \mathrm{~mm}$, and a gauge length of $108 \mathrm{~mm}$ were tested in a Zwick Z250 Materials testing machine (MTM) with fixed-fixed ends, as recommended by van Zijl et al. (2015) ${ }^{[10]}$. Three specimens were prepared by shotcrete process, following the shotcrete process intended for the overlay application. Three more specimens were prepared by casting.

From the results it is apparent that the sprayed SHCC has lower ultimate tensile strength $\sigma_{t u}$ and ultimate strain $\varepsilon_{t u}$ than specimens that were cast and vibrated. The shotcrete mix may be improved by further materials development, but is considered sufficient for the overlay application considered here.
Table 1: Sprayable SHCC mix proportions $\left(\mathrm{kg} / \mathrm{m}^{3}\right.$, except the fibre content in terms of volume fraction $V_{f}$ )

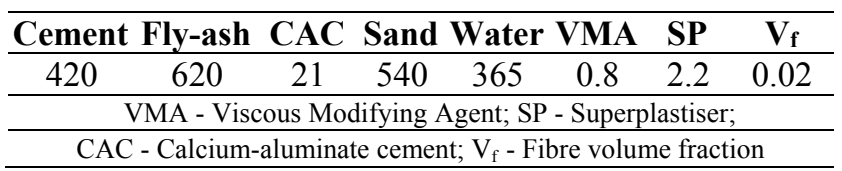

Table 2: SHCC tensile properties (coefficient of variation shown in brackets)

\begin{tabular}{ccc}
\hline & $\boldsymbol{\sigma}_{\boldsymbol{t u}}(\mathbf{M P a})$ & $\boldsymbol{\varepsilon}_{\boldsymbol{t u}}(\mathbf{\%})$ \\
\hline Shotcrete & $2.08(0.006)$ & $2.06(0.266)$ \\
\hline Cast & $2.97(0.072)$ & $3.16(0.337)$ \\
\hline$\sigma_{t u}, \varepsilon_{t u}-$ Ultimate tensile strength and strain \\
\hline
\end{tabular}

\subsection{Masonry adhesion and friction}

Triplet tests according to BS EN 1062-3 ${ }^{[12]}$ were performed in a $2 \mathrm{MN}$ Instron MTM on masonry specimens consisting of three clay bricks joined by two $10 \mathrm{~mm}$ mortar joints. Typical baked clay bricks from local industry for load-bearing masonry walling in the Western Cape were used together with a class I cement-based mortar. The bricks were prewetted to ensure an acceptably low water absorption rate from the fresh mortar. Nine specimens were prepared, of which three each were tested with $0,-0.3 \mathrm{MPa}$ and $-0.6 \mathrm{MPa}$ normal stress. In this way the joint interface adhesion could be determined to be $0.28 \mathrm{MPa}$, and the friction coefficient $\Phi=1.08$. The triplet test specimen and setup is shown in Fig. 5, showing the smooth front (left) and grooved rear (right) face of the clay bricks. $5 \mathrm{~mm}$ deep by $12 \mathrm{~mm}$ wide grooves are standard on these bricks for adherence of plaster.

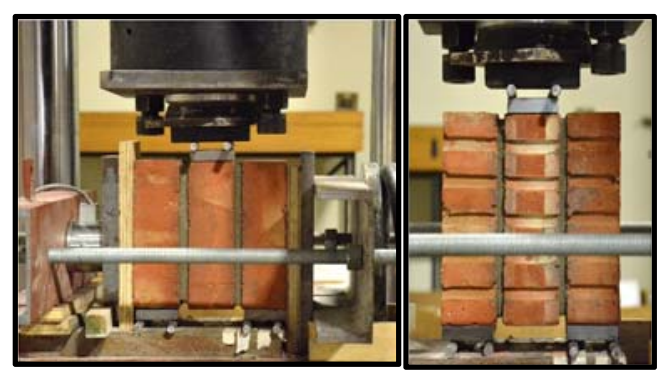

Figure 5: Triplet test setup acc. BS EN 1052-3 $3^{[12]}$ showing the smooth front faces of the bricks (left) and the grooved rear faces (right). 


\subsection{SHCC bond to masonry}

The triplet tests described in section 4.2 were repeated on 5 specimens onto which $30 \mathrm{~mm}$ SHCC overlays had been sprayed on both faces. After preparing the 5 masonry triplet specimens, they were air cured at $24 \pm 2^{\circ} \mathrm{C}$ and relative humidity of $65 \pm 5 \%$ for 7 days. The 30 mm overlays were then sprayed onto both faces, and troweled flat directly after spraying. The specimens were left in the laboratory to set for 24 hours, after which they were wrapped in plastic foil and kept in the same conditions for a further 13 days until testing. The tests were performed in the same $2 \mathrm{MN}$ Instron MTM.

The specimens failed in mode 2 , in some cases along more than simply the central SHCC-brick interfaces. From the load-slip responses of the control triplets (section 4.2) and those with overlays, it is clear that the mortar joint resistance is lost at significantly smaller shear-slip than at peak overlay bond resistance. For this reason the peak force of each overlay triplet specimen was divided by the SHCC-brick interface areas only to determine the ultimate bond stress to be 2.30 $\mathrm{MPa}$. The coefficient of variation was relatively high at 0.293 . Note that no distinction was made between the smooth face and the grooved face bond. So, the bond reflects an average value.

\subsection{SHCC shrinkage}

Shrinkage may pose a threat to overlay performance by interfacial delamination caused by the restraint to shrinkage by the substrate at the interface. Free and restrained shrinkage tests are currently being performed on the materials presented in the foregoing sections.

Current indications are that after two months no cracking or delamination has occurred in 30 $\mathrm{mm}$ SHCC overlays sprayed onto one face of roughly $1 \mathrm{~m}$ long and $220 \mathrm{~mm}$ high, single leaf masonry walls. The triplet tests described in subsequent sections were protected from drying by wrapping until the time of testing, to eliminate shrinkage from the current investigation. Larger walls with and without SHCC overlays, and subjected to drying will be reported in later publications, with due consideration of shrinkage.

\section{LARGE TRIPLET TESTS}

\subsection{Overlay design}

In order to verify the failure modes and an overlay design procedure, a relatively simple test was chosen in the form of a larger triplet test. Each specimen comprised nine clay bricks, attached with eight $10 \mathrm{~mm}$ mortar joints, as shown in Fig. 6. Apart from control specimens without overlays, two overlay thicknesses were chosen; thin, $10 \mathrm{~mm}$ overlays and $30 \mathrm{~mm}$ overlays, in both cases sprayed onto both faces of the masonry specimens.

The overlay thickness for mode 1, i.e. SHCC shear cracking, was calculated by keeping the mode 1 resistance $\left(F_{\text {model }}\right)$ less than the mode 2 resistance $\left(F_{\text {mode } 2}\right)$, from:

$$
\begin{gathered}
F_{\text {model }}=4 \tau_{s} h_{b} t_{s}+2 h_{b} w_{b}\left(c_{j}-\Phi \sigma\right) \\
F_{\text {mode2 }}=2 h_{b} t_{b} \tau_{b}+2 h_{b} w_{b}\left(c_{j}-\Phi \sigma\right) \\
t_{s}<\frac{t_{b} \tau_{b}}{2 \tau_{s}}
\end{gathered}
$$

where $t_{s}$ is the SHCC overlay thickness, $h_{b}, w b$, $t_{b}$ are the brick height $(222 \mathrm{~mm})$, width (105 $\mathrm{mm})$ and thickness $(70 \mathrm{~mm}), c_{j}$ is the mortar joint adhesion to the brick, $\tau_{b}$ is the SHCC-brick bond (2.3 MPa from section 4.3) and $\tau_{s}$ is the SHCC ultimate shear resistance. Considering the latter to be $50 \%$ more than the ultimate tensile resistance ${ }^{[11]}$, Eq. (5) demands that the overlay thickness should be less than $25 \mathrm{~mm}$. It was decided to apply $10 \mathrm{~mm}$ overlays on one set of specimens, to ensure that mode 1 would dominate, and $30 \mathrm{~mm}$ overlays to another set of specimens, to ensure mode 2 debonding.

\subsection{Specimen preparation and testing}

Eight large triplet specimens as shown in Fig. 6 were prepared with the materials described in the previous sections. The masonry walls were air cured at a temperature of $24 \pm 2^{\circ} \mathrm{C}$ and relative humidity of $65 \pm 5 \%$ for 7 days. 10 $\mathrm{mm}$ thick SHCC overlays were then sprayed onto both faces of three of the specimens, while $30 \mathrm{~mm}$ overlays were sprayed onto both faces of two specimens. The SHCC was troweled flat 
directly after spraying. The other 3 specimens were retained as control specimens. Note that more specimens were built: 2 more with $10 \mathrm{~mm}$ overlays and two more with $30 \mathrm{~mm}$ overlays, but they were discarded due to premature damage, or experimental errors.

After spraying, the specimens were left in the laboratory to set for 24 hours, after which they were wrapped in plastic foil and kept in the same conditions for a further 13 days until testing. The test setup in a $2 \mathrm{MN}$ Instron MTM is shown in Fig.6. Four LVDTs recorded the central shear-slip displacement. The test was performed at $0.5 \mathrm{~mm} /$ minute displacement of the Instron MTM cross-head.

\subsection{Large triplet test results}

The load versus average shearing displacement is shown in Fig. 7 for a typical masonry control specimen (C5) and the three specimens with $10 \mathrm{~mm}$ SHCC overlays. The peak loads are summarized in Table 3 in terms of the average of each set, with the coefficient of variation (cov) in brackets.

(a)

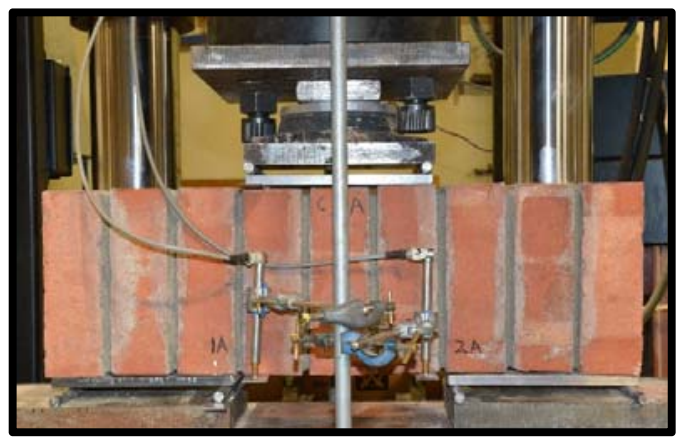

(b)

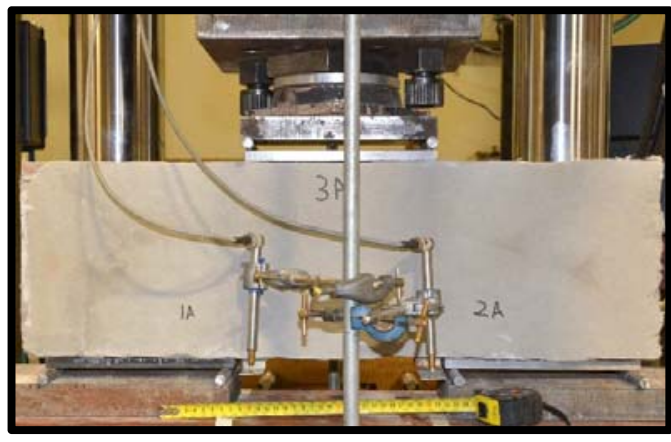

(c)

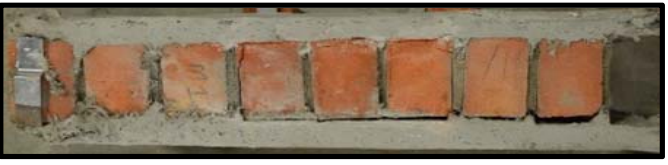

Figure 6: Larger triplet test setup, showing a specimen (a) without overlays, (b) with overlays and (c) delamination of the $30 \mathrm{~mm}$ thick overlays.

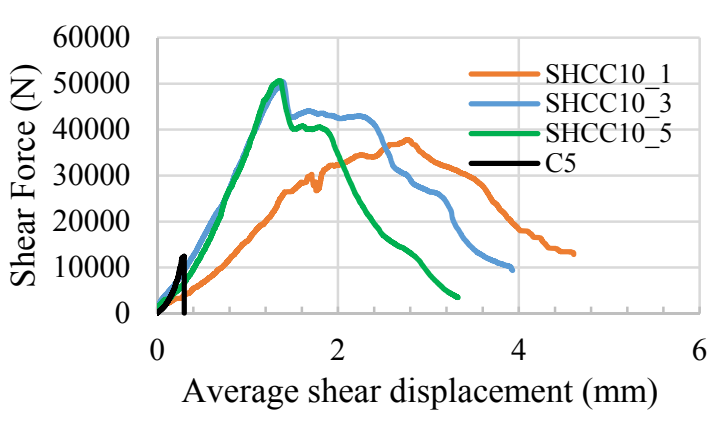

Figure 7: Larger triplet shear force-slip results.

Table 3: Large triplet results

\begin{tabular}{ccc}
\hline Triplet specimen & Shear force (N) & Shear stress (MPa) \\
\hline Masonry (3) & $11.6(0.537)$ & $0.29(0.537)$ \\
\hline 10 mm overlay (3) & $46.21(0.159)$ & $5.06(0.159)$ \\
\hline 30 mm overlay (2) & $58.14(0.038)$ & - \\
\hline (No. of specimens) & \multicolumn{2}{c}{ (Coefficient of variation) } \\
\hline
\end{tabular}

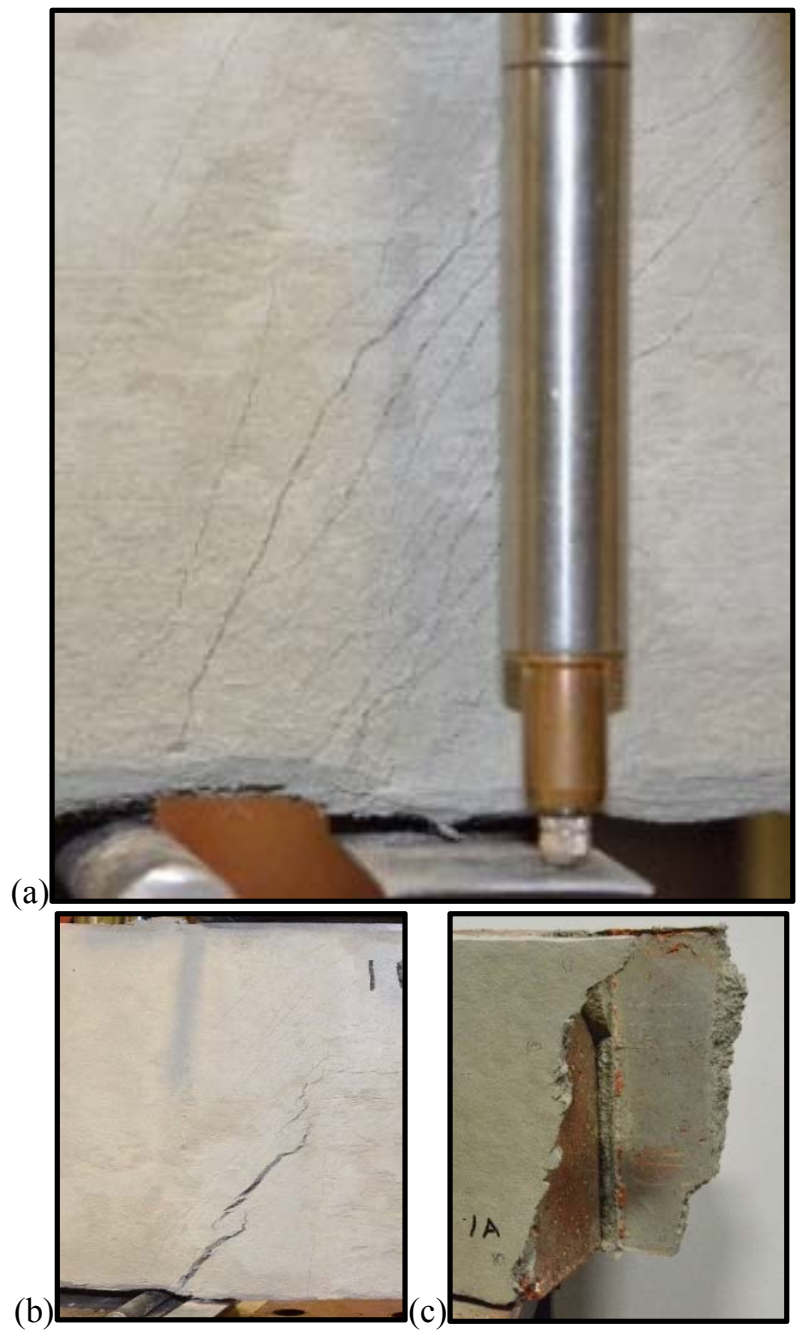

Figure 8: (a) Multiple cracks on the $10 \mathrm{~mm}$ overlay on the smooth brick face, (b) localised crack on the smooth face and (c) different failure on the smooth (front) than on the grooved (rear) brick face. 
The joint adhesion calculated from the control specimen results is $0.29 \mathrm{MPa}$, in close agreement with the $0.28 \mathrm{MPa}$ determined from the smaller triplet results in section 4.2. Note however the large cov of 0.537 . A significantly lower cov of 0.159 was found for the overlay specimens.

The overlays lead to an increase of roughly 4 times (10 mm overlays) and 5 times $(30 \mathrm{~mm}$ overlays) of the peak shear force compared to the control specimens. This means a 25\% increase in the resistance was brought about by the overlay thickness of $30 \mathrm{~mm}$ compared to the $10 \mathrm{~mm}$ overlays. This is clearly due to the different failure mechanisms. Interfacial delamination was the dominating failure mode in the specimens with $30 \mathrm{~mm}$ overlays (see Fig. 6c). Multiple, fine cracks formed in the $10 \mathrm{~mm}$ overlays, as shown in Fig. 8a. More cracks formed on the overlay attached to the smooth brick face than on the grooved face. The final localized crack formed in the shear zone, but inward from the failing mortar joint on the smooth brick face. The overlay on the grooved face had a more localized failure pattern, and was more vertical and adjacent to the failing mortar joint.

From Table 3 it is evident that a significantly higher ultimate shear strength developed in the SHCC overlays than used in section 5.1 for the estimation of interface layer thickness. There, the proposed value of 1.5 times the ultimate tensile strength was used for $\tau_{s}$ in Eq. (5). The shear strength of $5.06 \mathrm{MPa}$ (Table 3 ) is roughly 2.4 times the ultimate uniaxial tensile strength (Table 2).

\section{CONCLUSIONS}

SHCC overlays were successfully applied by shotcrete process to unreinforced masonry. From two series of triplet tests, one standard set for characterization, and another, larger specimen test for verification, the following conclusions are drawn.

- Two dominant modes of failure in shearing response of masonry with SHCC overlays are (i) multiple shear cracking in the SHCC overlays (mode 1), and (ii) debonding of the overlay from the masonry faces (mode 2 ).
- Mode 1 is a preferred failure mode, given the energy dissipation of multiple crack formation. The shear resistance of specimens with $10 \mathrm{~mm}$ overlays were four times that of control specimens without overlays, and significantly more ductile. Increasing the overlay thickness from 10 $\mathrm{mm}$ to $30 \mathrm{~mm}$ SHCC changed the failure mode to debonding as predicted, and increased the peak resistance by only $25 \%$.

- There is evidence that mechanical bond, here due to grooves in the brick faces sprayed with SHCC, lead to a more localized failure than a smoother interface. On the latter more cracks were observed in the mode 1 failure of specimens with $10 \mathrm{~mm}$ thick SHCC overlays.

In current work, drying shrinkage is included and larger shear walls are investigated for resistance to cyclic loading towards validation of SHCC overlays as a retrofitting strategy for improved seismic resistance of unreinforced load bearing masonry structures.

\section{REFERENCES}

[1] SANS 10160-4. 2011. Basis of structural design and actions for buildings and industrial structures. Part 4: Seismic actions and general requirements for buildings. Pretoria: SABS Standards Division, South Africa.

[2] Li, V.C., Wang, S., Wu, C. Tensile strainhardening behavior of PVA-ECC, ACI Materials Journal 98 (6) (2001) 483-492.

[3] Lin, Yi-Wei 2014. Strengthening of structures using ECC shotcrete. PhD dissertation, University of Auckland, New Zeeland.

[4] Van Zijl GPAG and Stander H 2009. SHCC repair overlays for RC: Interfacial bond characterization and modeling, CDROM Proc. International Conference on Concrete Repair, Rehabilitation and Retrofitting (ICCRRR 2008), University of Cape Town, South Africa, pp. 995-1003.

[5] Vermeltfoort, A. Th., Raijmakers, Th. M. J., and Janssen, H. J. M. 1993. Shear tests on masonry walls. Proc., 6th North American Masonry Conf., 1183-1193. 
[6] Van der Pluijm, R. 1992. Deformation controlled shear tests on masonry. Rep. BI92-104, TNO Building and Construction, Delft, The Netherlands (in Dutch).

[7] Van der Pluijm, R. 1998. Overview of deformation controlled combined tensile and shear tests. Rep. TUE/CCO/98.20, Eindhoven Univ. of Technology, Eindhoven, The Netherlands.

[8] Van Zijl, G. P. A. G., Rots, J. G., and Vermeltfoort, A. T. 2001. Modelling of shear-compression in Masonry. CDROMProc. 9th Canadian Masonry Symposium, P. H. Bischoff, J. L. Dawe, A. B. Schriver, and A. J. Valsangkar, eds., Fredericton, Canada.

[9] Van Zij1, G.P.A.G. 2004. Modeling Masonry Shear-Compression: Role of Dilatancy Highlighted. Journal of Engineering Mechanics 130(11): 12891296.

[10] van Zijl, G.P.A.G, Wittmann, F.H., Toledo Filho, R.D., Slowik, V., Mihashi, H. 2015. Comparative testing of crack formation in strain-hardening cement-based composites (SHCC). Materials and Structures, available online.

[11] van Zijl, G.P.A.G. 2007. Improved mechanical performance: Shear behaviour of strain-hardening cement-based composites (SHCC). Cement and concrete reseach 37:1241-1247.

[12] British Standard BS EN 1052-3. 2002. Method of test for masonry- Part 3 Determination of initial shear strength. BSI British standards. 